\title{
Do logging residue piles trigger extra decomposition of soil
} organic matter?

\section{Ojanen, Paavo}

2017-12-01

Ojanen , P , Mäkiranta , P , Penttilä , T \& Minkkinen , K 2017 , ' Do logging residue piles trigger extra decomposition of soil organic matter? ' , Forest Ecology and Management, vol. 405 , pp. 367-380 . https://doi.org/10.1016/j.foreco.2017.09.055

http://hdl.handle.net/10138/309511

https://doi.org/10.1016/j.foreco.2017.09.055

cc_by_nc_nd

acceptedVersion

Downloaded from Helda, University of Helsinki institutional repository.

This is an electronic reprint of the original article.

This reprint may differ from the original in pagination and typographic detail.

Please cite the original version. 


\title{
Do logging residue piles trigger extra decomposition of soil organic matter?
}

\author{
Paavo Ojanen, Päivi Mäkiranta, Timo Penttilä, Kari Minkkinen
}

\section{$\underline{\text { Abstract }}$}

Logging residue piles have been suggested to markedly increase the decomposition of the underlying peat soil leading to large carbon dioxide emissions. We aimed at scrutinizing this postulate with straightforward decomposition (mass loss) measurements. For the purpose, authentic soil organic matter (humus and peat) was incubated in mesh bags under piles and at control plots. The effect of piles was assumed to result from physical (shading and insulation on soil surface) and chemical-biological (leaching of nutrients and fresh organic matter) sources. To distinguish between the two, artificial piles of inorganic matter were established to mimic the bare physical effects. Enhancement of decomposition in the soil under the real and artificial piles was assessed by measuring the mass loss of cellulose strips.

Logging residue piles had clear physical effects on soil: temperatures were lowered and their diurnal variation subdued, and relative humidity at the soil surface was higher. The effect on soil moisture was also evident, but more variable, including both decreases and increases. These effects, mimicked by the artificial piles, decreased rather than increased cellulose mass loss. As the real piles, on the other hand, increased mass loss, we conclude that logging residue piles may enhance decomposition in soil due to chemicalbiological mechanisms.

Also the results on humus and peat mass loss indicate that piles can both increase and decrease decomposition. Consistent, remarkable increase in mass loss was not observed. Thus, our results do not support the postulate of logging residue piles dramatically increasing decomposition of soil organic matter. Rather, they hint that the effect of logging residue piles on soil is an interplay of physical and chemicalbiological effects and carbon transport via roots and fungi. To fully understand and quantify these effects, vertical $\mathrm{C}$ fluxes between piles and soil and horizontal $\mathrm{C}$ fluxes within soil need to be assessed in addition to decomposition in soil and piles.

Keywords: logging residue; decomposition; soil organic matter; peatland 


\section{Introduction}

Substitution of fossil fuels with bioenergy has been proposed as a way to reduce greenhouse gas emissions in our efforts to tackle climate change. Especially in the Nordic countries, a substantial new source of forest bioenergy has been logging residue that includes branches, foliage and tree tops (Helmisaari et al. 2014). Before this practice started, logging residue was typically left on site after logging.

The mitigation of climate change by substituting fossil fuels with logging residue has been criticized. Two major concerns have been raised: 1) The burning of residue for energy at once instead of letting it slowly decompose at the site decreases the forest's carbon (C) storage and thus considerably reduces the benefit of avoiding emissions from burning fossil fuels (e.g., Karlsson et al. 2014; Lindholm et al. 2011; Olajuyigbe et al. 2014; Repo et al. 2012). 2) The removal of nutrients with logging residue may decrease the forest's $C$ storage by slowing down the growth of the next tree generation (e.g., Achat et al. 2015; Curzon et al. 2014; Holub et al. 2013; Wall \& Hytönen 2011; Wei et al. 2000) and thus further reduce the benefits of substituting fossil fuels. Mäkipää et al. (2014) modeled both effects and concluded that harvesting logging residue reduced the average $C$ storage of forest during a forest rotation more than burning logging residue reduced $\mathrm{C}$ emissions by substituting diesel oil.

So far, one aspect of leaving versus harvesting logging residue has received little attention: Logging residue may stimulate decomposition processes of soil organic matter (SOM) in the underlying soil (Adamczyk et al. $2015,2016)$. Usually the harvester leaves the logging residue in piles at the site, each pile typically consisting of the branches, foliage and top of one harvested tree. These piles may affect physical conditions, namely temperature and moisture of the underlying soil (Roberts et al. 2005) by providing insulation and shading on the soil surface. Also, precipitation leaches mineral nutrients from the piles to soil (Wall 2008) and the piles serve as a source of fresh organic $C$ that can cause priming of decomposition in soil (Karhu et al. 2016, Kuzyakov et al. 2000). These physical and chemical-biological effects can alter microbial processes in soil and thereby affect the carbon dioxide $\left(\mathrm{CO}_{2}\right)$ emissions from SOM decomposition.

As far as we know, only Mäkiranta et al. (2012) have quantified the impacts of logging residue piles on soil $\mathrm{CO}_{2}$ emissions or soil $\mathrm{C}$ balance. They studied a forestry-drained peatland after clearfelling and found that logging residue piles increased forest floor respiration by more than twice compared to the mass loss from the residue. In just two growing seasons following clearfelling, a remarkable extra release of $\mathrm{CO}_{2}$ by $680 \pm 220 \mathrm{~g} \mathrm{C} \mathrm{m}^{-2}$ was detected. It was postulated to result from the increased decomposition of peat soil under the logging residue piles. Neither the physical and chemical-biological effects of logging residue piles nor SOM decomposition were measured, however. Thus, no conclusions on how the piles may have caused the increase in SOM decomposition could be drawn. Also, results from one site only raise the question if the phenomenon pertains forestry-drained peatlands in general.

If decomposition of SOM is increased because of physical effects, it could be controlled by simply scattering the residues instead of piling them. If the increase is due to chemical-biological effects, the scattering of residues would not help as much. Also, it is important to know if the increased SOM decomposition originates from the fresh SOM at the soil surface that would anyway decompose during a few years. In peatlands, carbon can also be released from peat that constitutes a long-term $C$ storage.

The most straightforward way to estimate the effect of logging residue piles on soil $\mathrm{C}$ storage and thus on $\mathrm{CO}_{2}$ emissions would be repeated soil sampling after clearfelling. Unfortunately, peat soil C storage is so big and variable that even long-term studies (Simola et al. 2012, Minkkinen \& Laine 1998) addressing an order 
of magnitude higher $\mathrm{C}$ storage changes than those observed by Mäkiranta et al. (2012) have yielded very uncertain estimates. This problem of spatial heterogeneity can be solved by following the mass loss of samples with known mass, a widely used method especially in litter decomposition studies (e.g., Grover \& Baldock 2010, Straková et al. 2012, Tuomi et al. 2009, Vitt et al. 2009,).

We aimed at scrutinizing the postulate that logging residue piles increase the decomposition of SOM. The effect of logging residue piles on decomposition in soil was estimated by incubating both authentic SOM samples and cellulose strips in situ at different depths. Experiments on three study sites with varying drainage intensity and soil fertility were established to evaluate how site specific or general these effects are. To distinguish between physical and chemical-biological effects, "artificial logging residue piles" providing shading and insulation but not leaching organic matter or nutrients to soil were constructed on one of the study sites.

\section{Material and methods}

\subsection{Study sites}

Three forest stands (Tables $1 \& 2$ ) were chosen in the vicinity of Hyytiälä Forestry Field Station, Southern Finland, among stands that had been harvested during the winter 2012-2013. The stands were clearfelled with the cut-to-length method following the standard forestry procedure of Metsähallitus (the agency that manages Finnish state forests), their planning and logging personnel having no knowledge of the forthcoming study. An approximately 50×50 m study site was delimited at the center of each stand. Logging residue piles covered 23 to $35 \%$ of the site area (Table 3 ).

The sites were chosen to represent different levels of drainage intensity and fertility with different proportions of tree species (Tables 1 \& 2). Sites A and C represent the Dwarf shrub site type (Laine 1989), which is the least fertile type where forestry is still economically viable. Site $B$, on the other hand, represents the more fertile Vaccinium myrtillus site type. The difference in fertility is reflected both in tree stand and ground vegetation composition. By stem volume, Scots pine (Pinus sylvestris) dominated the tree stand at all the sites (Table 2). Differing from the poorer sites, site B had a dense understory of Norway spruce (Picea abies). Although not affecting much the total stem volume, spruce with its dense and long crown was a major component in the logging residue piles at that site. Also downy birch (Betula pubescens) was abundant in the understory at all sites, but branches and twigs of its leafless crowns were rather scattered and contributed little to the logging residue piles. Dwarf shrub projection coverage at the nutrient poor sites $A(19 \%)$ and $C(14 \%)$ was higher compared to the nutrient rich site $B(9 \%)$. Site $B$, in turn, had higher forb coverage (9\%) compared to sites $A(1 \%)$ and $C(4 \%)$. Site $C$ had high peat moss coverage (14\%) and abundant cottongrass (Eriophorum vaginatum, 3\%), reflecting poor drainage at that site (Table 1).

The sites had virtually the same elevation and were located within a radius of $650 \mathrm{~m}$ (Table 1), thus having virtually the same weather conditions. Precipitation and air temperature were obtained from the Siikaneva measurement station (see Mathijssen et al. 2016 for site description), located one kilometer from our study sites. Daily mean temperature was $14.3^{\circ} \mathrm{C}$ and precipitation sum was $227 \mathrm{~mm}$ during June-September 2013. 


\subsection{Experiment lay-out}

At each site, five logging residue piles distributed evenly around the site were selected as treatment plots (LRP). At sites A and C, each pile clearly consisted of branches and foliage of a single pine tree and the piles were rather even in size. The piles were somewhat smaller at site $C$ than at site $A$. The area covered by a single pile was about $1 \mathrm{~m}^{2}$. At site $B$, piles varied in size and contained a varying mixture of pine and spruce residues. There, the five piles were selected by visual inspection so that they represented the distribution of all available piles in terms of size and species composition. We did not try to estimate the masses of needles and woody components in each pile: A precise estimation would have required tearing apart the piles, and we wanted to disturb the structure of the piles as little as possible.

In the vicinity of each treatment plot, a control plot (area $1 \mathrm{~m}^{2}$ ) without any logging residue (CTRL) was marked. The CTRL plots were placed so that they were at least two meters apart from any pile. This was as far as it was possible to get from piles without manipulating the sites.

At site A, also 15 artificial logging residue piles (ART) were constructed during the last days of May 2013, to distinguish between physical and chemical-biological effects of the piles. The main body of the artificial piles consisted of polystyrene foam peanuts, used to mimic the thermal insulation and shading by logging residue, but without leaching of $\mathrm{C}$ or nutrients. A plastic mesh netting was placed on top of each pile to restrain the lightweight peanuts. Finally, the piles were covered with green camouflage netting to gain radiation properties equivalent to logging residue piles. As the magnitude of insulation by logging residue piles was not known prior to the experiment, differing amounts of foam peanuts were used to gain three levels of treatment (ART min: $7 \mathrm{l} / \mathrm{m}^{2}, A R T_{\text {medium }}: 15 \mathrm{l} / \mathrm{m}^{2}, A R T_{\max }: 30 \mathrm{l} / \mathrm{m}^{2}$ ), each consisting of five artificial piles.

\subsection{Mass loss of soil organic matter}

The effect of logging residue piles on the decomposition of SOM was tested with authentic, site-specific humus and peat samples at CTRL and LRP plots. The samples were collected on June $5^{\text {th }}, 2013$ at each site from one representative area of approximately $2 \times 2 \mathrm{~m}$ to avoid excessive variation in the parent material.

First, aboveground parts of vascular plants and the layer of living mosses were clipped and removed. Then the distinct humus layer formed after drainage (the top few centimeters of soil profile) was harvested by hand and knives. As this material was rather heterogeneous, it was mixed and chopped by hand to a more homogeneous mass. Cones, big pieces of wood and other particles large enough to impede the accurate estimation of sample moisture content were removed. Then, 20 subsamples were dried at $105^{\circ} \mathrm{C}$ to estimate the moisture content of the homogenized humus. Finally, six mesh bags (mesh size $100 \mu \mathrm{m}$ ) for each CTRL and LRP plot were filled with humus samples of known fresh mass collected from the respective site (sample size on average corresponding to dry mass of $11 \mathrm{~g}$ ). The mesh size was small enough to keep the material in. It also allowed hyphae important for decomposition of SOM but not roots to enter the bag (Grover \& Baldock 2010).

After the humus layer had been collected, undisturbed peat samples ("original peat sample" in the mixed models) were taken from the top $20 \mathrm{~cm}$ of peat. The samples were taken with a box type peat corer with cross-sectional area of $8 \times 8 \mathrm{~cm}$. Each sample was divided into 0-10 and 10-20 cm layers and then cut vertically with a sharp knife into five $1.5 \mathrm{~cm}$ thick slices. One of the slices was dried at $105^{\circ} \mathrm{C}$ to estimate the sample moisture content. The remaining four slices were weighed for fresh mass (corresponding to on 
average $6.4 \mathrm{~g}$ of dry mass) and inserted into mesh bags (mesh size $100 \mu \mathrm{m}$ ). Six mesh bags for the $0-10 \mathrm{~cm}$ layer and six bags for the 10-20 cm layer with peat collected from the respective site were prepared for each CTRL and LRP plot.

On the following day, June $6^{\text {th }} 2013$, six replicates of humus and peat bags were placed at each plot. The humus bags were inserted horizontally inside the humus layer. The peat bags were inserted vertically to the respective $0-10$ and $10-20 \mathrm{~cm}$ peat layers. Three replicates were recovered after four months, on September $30^{\text {th }}$. The other three replicates were recovered after two years, on May 1st, 2015. External material was removed from the samples, which were then dried at $105^{\circ} \mathrm{C}$ and weighed. Mass loss was calculated as the difference between initial and final dry masses divided by initial dry mass (= percentage of initial mass lost). The data on initial humus moisture content from site $\mathrm{C}$ were lost, and site $\mathrm{C}$ was excluded from the statistical test of humus decomposition.

The effect of logging residue piles on SOM mass loss was tested with linear mixed models, separately for humus layer (eq. 1, nlme, Pinheiro et al. 2013) and peat (eq. 2, Ime4, Bates et al. 2014; due to the crossed random effects) using $\mathrm{R}$ (version 3.0.2, R Core Team 2013). In the model for humus layer, the interactions of incubation time ( 4 months and 2 years) and treatment (CTRL and LRP) (parameters $\beta_{\text {timextreatment }}$ ) and in the model for peat the interactions of incubation depth, time, and treatment (parameters $\beta_{\text {timexdepthxtreatment }}$ ) were included as fixed factors. Interactions of time and plot (parameters $\gamma_{\text {timexplot }}$ ) (or interactions of time, plot and depth (parameters $\gamma_{\text {timexplotxdepth }}$ ) for peat) were included as random factors, because of the three replicates at each time, plot and depth. For peat, also interactions of time, depth and original peat sample (sample) (parameters $\gamma_{\text {depthxtimexsample) }}$ were included as random factors. The statistical significance of the fixed factors was examined through $p$-values obtained by likelihood ratio tests of the full model against model without the fixed factor: First, the significance of time and depth were tested. Second, the significance of the models with treatment was tested against models without treatment.

mass loss of humus $=\beta_{\text {timextreatment }}+\gamma_{\text {timexplot }}$

mass loss of peat $=\beta_{\text {timexdepthxtreatment }}+\gamma_{\text {timexplotxdepth }}+\gamma_{\text {depthxtimexsample }}$

\subsection{Mass loss of cellulose}

The effect of logging residue piles and artificial piles on decomposition in soil was tested also with cellulose strips $(0.1 \times 2 \times 10 \mathrm{~cm}$, dry mass on average $1.7 \mathrm{~g})$. At each CTRL, LRP and ART plot, three sets of strips, packed in mesh bags (mesh size $1 \mathrm{~mm}$ ), were inserted into soil on June $6^{\text {th }}, 2013$. Each set had five strips: one horizontally below living mosses (surface) and four vertically at different depths (0-10, 10-20, 20-30 and $30-40 \mathrm{~cm}$ ). The strips were recovered four months later, on September $30^{\text {th }}$. They were cleaned from external material, and dried at $105^{\circ} \mathrm{C}$. Mass loss was calculated as the difference between initial and final dry masses divided by initial dry mass (= percentage of initial mass lost).

The effect of logging residue piles and artificial piles on cellulose mass loss was tested with linear mixed models (eq. 3, nlme, Pinheiro et al. 2013). The models had interactions of depth and treatment (parameters $\beta_{\text {depthxtreatment }}$ (CTRL \& LRP: model including all sites for testing the effect of LRP; CTRL, LRP, ART min, $A R T_{\text {medium }}$ $\& A R T_{\max }$ : model including only site $A$ for testing the effect of ART treatments) as fixed variables. The interactions of plot and depth (parameters $\gamma_{\text {plotxdepth }}$ ) were included as random factors. The statistical 
significance of the fixed factors was examined through $p$-values obtained by likelihood ratio tests of the full model against model without the fixed factor similarly to the peat decomposition model (eq. 2).

mass loss of cellulose $=\beta_{\text {depthxtreatment }}+\gamma_{\text {plotxdepth }}$

\subsection{Soil temperature and moisture}

Three temperature loggers (iButton DS1921G and DS1922L, Maxim Integrated, USA) were placed in the center of each LRP and CTRL plot: one at the soil surface below living mosses, one at $5 \mathrm{~cm}$ below the soil surface and one at $15 \mathrm{~cm}$ below the soil surface. ART plots had one logger each at the soil surface. Temperatures were logged at every two hours during June-September 2013, the time period of the main study. For the October 2013-September 2014 period, 5 and $15 \mathrm{~cm}$ temperatures were logged at only two LRP and two CTRL plots at each site at every three to four hours.

For water table measurements, six perforated plastic tubes on each study site were permanently installed midway between the paired LRP and CTRL plots. Water table depth from the soil surface was measured from each tube seven times during June-August, 2013.

Relative humidity was measured at the moss layer-atmosphere interface once in an hour from July $5^{\text {th }}$ to September $30^{\text {th }} 2013$ using capacitive humidity loggers (DS1923, Maxim Integrated, USA). "RH Temperature Compensation" and "Software Saturation Drift Compensation" correction algorithms provided by the manufacturer were applied. Due to the high price of the loggers, they were placed only at two CTRL plots and three LRP plots at each site and at one to two $A R T_{\min }, A R T_{\text {medium }}$ and $A R T_{\max }$ plots.

Tea bags containing ordinary black tea, installed below the living moss layer were used as a low-cost means to monitor top soil moisture. We assumed that tea bag as organic matter would exhibit similar moisture content dynamics with its surroundings. At each CTRL, LRP and ART plot, 10 dry tea bags were installed at the beginning of June. One bag per plot was recovered on six occasions during June-August. Bags were weighed, dried at $105^{\circ} \mathrm{C}$, and weighed again to estimate gravimetric water content.

\section{Results}

\subsection{Mass loss of soil organic matter}

Mass loss of humus was markedly higher $(p<0.0001)$ after two years (mean $47 \%)$ than after four months (19\%), both sites A and B showing a similar trend (Figure 1, Appendix 1). LRP showed site-specific effects: Mass loss increased at site $A(p=0.0094)$ and decreased at site $B(p=0.0001)$. The magnitude of the effect was smaller after two years than after four months, especially at site $B(-0.1 \%$-units vs. $-5.2 \%$-units). When the sites were modeled together, the LRP did not affect mass loss $(p=0.76)$.

Absolute humus mass loss for site $\mathrm{C}$ was not available but, based on the ratio of dry mass after two years and initial fresh mass, LRP increased mass loss after two years $(p=0.02)$. This relative increase of $12 \%$ was of the same order of magnitude than at site $A$ (relative increase of $6 \%$ ).

LRP showed site-specific effects on peat mass loss (Figure 1; $A: p=0.03, B: p=0.02, C: p=0.02$ ). The effects were varying even within the sites: both increases and decreases were observed (Figure 1, Appendix 1). 
Therefore, LRP showed no significant treatment effect when the results for all sites were analyzed together $(p=0.13)$. Even the effects of depth $(p=0.19)$, time $(p=0.19)$, and their interaction $(p=0.28)$ were not significant. Mass loss of peat was much higher at the site $C$ than at the other sites, mainly due to the high mass loss of the 10-20 cm layer samples (Figure 1, Appendix 1).

Mass loss of peat at site B showed exceptionally high variation among samples in the $0-10 \mathrm{~cm}$ layer for the two-year samples for both CTRL and LRP (see standard deviation in Figure 1 \& Appendix 1 ). This was due to two distinct values for CTRL (-10\% and $-19 \%)$ one distinct value at LRP (-26\%) (Appendix 2). On the contrary, the high variation at site $C$ in the $10-20 \mathrm{~cm}$ layer for the four-month samples was not due to single distinct values. There, mass loss varied considerably between samples originating from different original peat samples. This caused a wide, bimodal distribution of mass loss values (Appendix 2).

\subsection{Mass loss of cellulose}

LRP increased the mass loss of cellulose ( $p=0.0001$, Figure 2$)$. The effect was on average $5.1 \%$-units, or $36 \%$ relative to mass loss at CTRL (Table 4$)$. Increasing depth decreased mass loss ( $p<0.0001$ ), mass loss being an order of magnitude lower in the deepest layer $(30-40 \mathrm{~cm})$ than in the surface layer. The decreasing trend towards deeper layers was observed at all sites. Also the effect of LRP along with its statistical significance decreased towards deeper soil layers (Table 4). This seemed to be due to decrease in mass loss in general towards deeper layers, and the relative effect of LRP (\% of mass lost at CTRL) did not show a decreasing trend.

Mass loss in the 10-40 cm layers was clearly slower at the $B$ and $C$ sites than at the $A$ site (Figure 2 ). This coincided with the higher water table $(20-30 \mathrm{~cm}$ ) at those sites (Table 1), probably causing anoxia in the soil. At the A site, water table was deep $(65 \mathrm{~cm})$ and even the deepest layers showed considerable mass loss (mean $7.4 \%$ and $9.6 \%$ at the $20-30$ and $30-40 \mathrm{~cm}$ layers on CTRL plots).

Artificial logging residue piles did not increase mass loss of cellulose ( $p=0.87$, Figure 2$)$. In the surface to 20 $\mathrm{cm}$ layers, there was no significant effect and in the 20-30 and 30-40 cm layers $A R T_{\min }(p=0.05$ and 0.08$)$ and $A R T_{\text {med }}(p=0.05$ and 0.11$)$ treatments even decreased decomposition.

\subsection{Soil temperature and moisture}

Daily mean soil temperature was $1-2{ }^{\circ} \mathrm{C}$ lower at LRP plots than at CTRL plots consistently at all sites and measurement depths during the growing season 2013 (Figure 3 \& Appendix 3). Daily temperature amplitude (= difference between the maximum and minimum temperatures of the day) was ca. $50 \%$ lower at LRP plots at all sites, but the absolute value of this difference was clearly depth-dependent: At the surface, the amplitude at LRP plots was ca. $6{ }^{\circ} \mathrm{C}$ lower and at $15 \mathrm{~cm}$ depth only $0.2-0.4{ }^{\circ} \mathrm{C}$ lower. The few loggers left for the next year (data not shown) showed no clear differences in temperature variables between CTRL and LRP plots during winter. During summer 2014, CTRL and LRP plots showed similar differences than in 2013 at the B site, somewhat smaller differences for the A site, and no observable differences for the $\mathrm{C}$ site. 
The effect of artificial LRP on mean surface temperature was on average similar to LRP (Figure 3), but surface temperature dropped more during September (Appendix 3 ). The reduction of temperature amplitude under $A R T_{\max }$ was similar to $L R P$, but less pronounced at $A R T_{\text {min }}$ and $A R T_{\text {medium. }}$.

LRP kept relative humidity high during the July-August period at all the sites, while at the CTRL plots humidity considerably dropped during daytime (Figure 4). ART treatments had similar effect to LRP, especially ART max.

LRP affected also top soil gravimetric water content at all the sites (Figure 5). At the start of the treatment, soil was drier under LRP at the B and C sites. By July $2^{\text {nd }}$, after a modestly rainy week (Appendix 4 ), soil had become wetter both at CTRL and LRP plots. During July-beginning of August, soil water content at CTRL plots at all the sites got gradually drier, coinciding with a period of low rainfall (Appendix 4) and lowering water table (data not shown). At LRP plots, soil stayed relatively wet until the beginning of August. By August $20^{\text {th }}$, soil had become wetter again, especially at LRP plots. This was preceded by a rainy week, with an especially high rainfall at August $14^{\text {th }}$. Also the ART treatments had an effect on top soil moisture, but none of them mimicked the effect of LRP throughout the whole period (Figure 5).

\section{Discussion}

The effect of logging residue piles on the mass loss of SOM (Figure 1) varied between sites according to soil fertility and residue composition. At the nutrient-rich site with piles consisting of a mixture of pine and spruce residue, the piles reduced mass loss of both humus and peat after four months. After two years, this effect had disappeared. At the poorer sites with piles consisting solely of pine residue, the mass loss of humus increased. At those sites, piles showed no consistent effect on peat mass loss.

The mass loss rates as such were reasonable. The mass loss of peat was much lower than that of humus, as one would expect: Peat is old, highly decomposed material enriched with recalcitrant substances, while the humus layer mainly consists of fresh organic matter derived from litter production of recent years. Mass loss of peat was comparable to that estimated by Vitt et al. (2009) in an in situ incubation study of boreal fens in Canada. Mass loss of humus was within the wide variation of mass losses of different litter types in boreal mires in Finland (Straková et al. 2012).

Between-site variation in the mass loss of peat appeared to be related to water table as the peat samples of the wettest site (Table 1 ) incubated closest to the water table clearly showed the highest mass loss (Figure 1). Also Grover \& Baldock (2010) and Belyea (1996) have reported higher mass loss in the zone of water table fluctuation than in layers closer to soil surface. It has been attributed to the good availability of both oxygen and water promoting decomposition in the zone of water table fluctuation (Grover \& Baldock 2010).

For humus and also in most cases for peat, random variation between mass loss samples was small enough so that treatment effects could be reliably estimated. By using fresh slices of peat for incubation we were also able to avoid artefacts caused by drying of samples before incubation (Taylor 1998). On the other hand, using unhomogenized peat samples led to high between sample variation in some cases, even though the peat samples were taken within an area of only few square meters at each site. In addition to actual differences in the decomposability of peat samples, this can have resulted from heterogeneity in peat moisture content: The initial dry masses of the peat slices were calculated based on their fresh masses 
and the moisture content of an adjacent peat slice. Both these sources of variation are random by nature and should not bias the results. But as the mass loss of peat is low in the time scale of few years, random variation between samples may hamper the estimation of statistically significant treatment effects.

Logging residue piles consistently affected physical conditions in peat soil. The effects of increased thermal insulation and shading under logging residue piles on soil temperature (Figure 3 ) and relative humidity (Figure 4) were unambiguous: temperatures did not rise as high during the summer as without piles, and the diurnal variation in temperature and relative humidity was subdued. These effects were also reproduced with the artificial piles.

The effect of logging residue piles on surface soil moisture (Figure 5) was also evident but variable, including both increases (mainly during the late season) and decreases (mainly during the early season). This variability is probably due to two contrasting mechanisms affecting soil moisture: 1 ) Logging residue piles intercept a major part of the precipitation (Wall 2008) and thus prevent the soil underneath from wetting during minor rain events. 2) Logging residue piles decrease the loss of soil moisture due to evaporation, as they keep the soil surface colder and hinder air mixing above the soil surface. Thus, it is understandable that the surface soil underneath the piles was drier in the beginning but once it got wet, it stayed wetter. Considering that the polystyrene foam peanuts in the artificial logging residue piles have negligible water retention capacity, it is also understandable that the artificial piles in many occasions did not have the same effect on soil moisture as the logging residue piles had.

As decomposition processes are strongly temperature dependent (e.g., Mäkiranta et al. 2009, Lloyd \& Taylor 1994), the lower temperatures under logging residue piles (Figure 3) should slow down decomposition. Due to the exponential nature of the temperature dependency, also the subdued diurnal variation should decrease the average decomposition rate. Thus, if only temperature changes were affecting soil processes, logging residue piles should have decreased the mass loss of SOM (Figure 1). Decreased mass loss was indeed observed at the fertile site after four months. Even mass gain was observed in peat under spruce-pine piles which may indicate substantial dissolved organic C (DOC) leaching from the piles adding mass to soil. After two years the decreasing effect on mass loss had disappeared, however. At the poorer sites the piles even enhanced mass loss of humus. These findings suggest that logging residue piles had a chemical-biological priming effect on SOM decomposition. This was supported by the results of the cellulose mass loss experiment (Figure 2): Cellulose mass loss in the top soil was clearly enhanced under the real logging residue piles whereas under the artificial piles no change and even decrease in the deeper layers was observed.

Even though indicating priming of decomposition, our results do not support the postulate by Mäkiranta et al. (2012) suggesting markedly increased SOM decomposition due to logging residue piles. To be comparable with their results, we should have observed an on average 5-10\%-unit increase in the mass loss of humus and peat due to logging residue piles after two years. Had the effect been concentrated in the humus layer that has the highest decomposability, the humus layer samples should have completely disappeared. We found no evidence of such mass loss increase at any of the three sites (Figure 1), despite the study material in this study and that of Mäkiranta et al. (2012) being very much alike: The site types in both studies varied similarly from Dwarf-shrub type to Vaccinium myrtillus type. Second, the sites of the two studies were located only $70 \mathrm{~km}$ apart and weather conditions were rather similar during the studies: Although precipitation was somewhat higher in the Mäkiranta et al. (2012) study (297 vs. 227 [this study] 
$\mathrm{mm}$ in June-September), mean soil temperatures at $5 \mathrm{~cm}$ depth in the control plots were virtually identical (13.4 vs. 13.3 [this study] ${ }^{\circ} \mathrm{C}$ ).

A possible explanation for the seemingly contradictory results is that the extra $\mathrm{CO}_{2}$ efflux due to logging residue piles observed by Mäkiranta et al. (2012) did not result from increased decomposition of SOM (Figure 6). They did not directly measure the decomposition of SOM. Instead, the difference between respiration measured at control and logging residue plots being larger than the mass loss of logging residues ( $=$ direct $\mathrm{CO}_{2}$ emissions from residue + decomposition of $\mathrm{DOC}$ leached from residue to soil) was assumed to result from enhanced SOM decomposition. As their measurement plots were not isolated from the adjacent soil, saprotrophic fungi could have translocated organic carbon to measurement plots via their cord systems (Boddy 1993; Pritchard et al. 2008; Thompson \& Rayner 1983; Vargas \& Allen 2008) and then respired it for energy for their growth and resource acquisition. Increased respiration would also occur due to decomposition of the fast-renewing hyphae (Atkinson \& Watson 2000; Staddon et al. 2003). The sudden emergence of logging residue piles creates spots with high amounts of available nutrients and easily decomposable organic compounds. Fungi are likely to compete for this resource by utilizing carbon translocated from adjacent areas. Fungi are able to sense their environment for available resources (Bahn et al. 2007; Brand \& Gow 2009) and cord-forming fungi have been shown to translocate both nutrients and carbon to connect and utilize resources in heterogenic environments (Cairney 2005; Dowson et al. 1986; Frey et al. 2003; Lindahl \& Olsson 2004; Wells et al. 1990).

Also ground vegetation growing next to logging residue piles may increase its carbon allocation to fine roots and associated mycorrhiza extending under the piles to acquire nutrients (Hodge 2004, Robinson 1994). The role of this root-related activity is, however, likely to be minor compared to that of the saprotrophic fungi during the first years after clearfelling: Ground vegetation visibly suffers from the abrupt increase in light intensity following clearfelling and its production is very low. At the study site of Mäkiranta et al. (2012), gross primary production of ground vegetation was only $80 \mathrm{~g} \mathrm{C} \mathrm{m}^{-2}$ during the first growing season and $120 \mathrm{~g} \mathrm{C} \mathrm{m}^{-2}$ during the second growing season. These values are so low that they could explain only a fraction of the observed extra $\mathrm{CO}_{2}$ efflux from plots with logging residue.

While plausible, the postulate that carbon translocation by fungal cord systems to logging residue piles and underlying soil causes marked $\mathrm{CO}_{2}$ efflux needs to be directly tested. An experimental setup to simultaneously measure the effect of piles on total $\mathrm{CO}_{2}$ efflux and mass loss of logging residues and SOM would be needed. Also, carbon translocation by fungi and ground vegetation should be assessed, for example by applying isotopic labeling (e.g., Frey et al. 2003; Leake et al. 2001). The different results from the mass loss of cellulose strips versus SOM also stress the importance of applying and further developing methods using authentic soil organic matter when studying the decomposition of SOM.

\section{Conclusions}

Logging residue piles had consistent physical effects on soil temperature and moisture. These effects decreased rather than increased decomposition in soil. On the other hand, our results also suggest that the piles have a positive chemical-biological priming effect on decomposition. Likely due to these opposing effects and DOC leaching from piles, SOM mass loss showed both increases and decreases due to logging residue piles. 
The postulate of dramatic increase in peat soil decomposition under logging residue piles (Mäkiranta et al. 2012) was not supported. We speculate that the earlier observation of increased $\mathrm{CO}_{2}$ efflux rather resulted from a release of carbon translocated by fungi and roots than from increased loss of soil $\mathrm{C}$ under logging residue piles. Thus, piling of logging residue does not seem to cause considerable extra $\mathrm{CO}_{2}$ emissions due to enhanced SOM decomposition.

To fully understand and quantify the effects of logging residue piles on decomposition processes in soil, a more comprehensive experimental setup would be needed. Vertical $\mathrm{C}$ fluxes between piles and soil and horizontal $\mathrm{C}$ fluxes within soil need to be assessed in addition to decomposition in soil and piles.

\section{Acknowledgements}

María Luisa Gutiérrez de los Ríos, Angela Lafuente Garcia-Ubero, Marta Martín and Janne Sormunen did most of the field and laboratory work. Peat nitrogen and carbon concentrations were analyzed by the laboratory of the Finnish Forest Research Institute Parkano Unit. Pavel Alekseychik provided weather data from the Siikaneva study site. Petra Straková has been developing the methods and tools for the decomposition experiments. This work was supported by the Environmental Research Pool of the Finnish Energy Industries (Energiateollisuuden ympäristöpooli). 


\section{$\underline{\text { References }}$}

Achat, D.L., Deleuze, C., Landmann, G., Pousse, N., Ranger, J., Augusto, L. 2015. Quantifying consequences of removing harvesting residues on forest soils and tree growth - A meta-analysis. Forest Ecology and Management 348, 124-141. http://dx.doi.org/10.1016/j.foreco.2015.03.042

Adamczyk, B., Adamczyk, S., Kukkola, M., Tamminen, P., Smolander, A. 2015. Logging residue harvest may decrease enzymatic activity of boreal forest soils. Soil Biology \& Biochemistry 82, 74-80. http://dx.doi.org/10.1016/j.soilbio.2014.12.017

Adamczyk, S., Kitunen, V., Lindroos, A-J., Adamczyk, B., Smolander, A. 2016. Soil carbon and nitrogen cycling processes and composition of terpenes five years after clear-cutting a Norway spruce stand: Effects of logging residues. Forest Ecology and Management 381, 318-326.

http://dx.doi.org/10.1016/j.foreco.2016.09.034

Atkinson, D., Watson, C. 2000. The Beneficial Rhizosphere: a dynamic entity. Applied Soil Ecology 15, 99104.

Bahn, Y-S., Xue, C., Idnurm, A., Rutherford, J., Heitman, J., Cardenas, M. 2007. Sensing the environment: lessons from fungi. Nature Reviews 5, 57-69. http://dx.doi.org/10.1038/nrmicro1578

Bates, D., Maechler, M., Bolker, B.M., Walker, S. 2014. Lme4: Linear mixed-effects models using Eigen and S4. ArXiv e-print; submitted to Journal of Statistical Software. http://arxiv.org/abs/1406.5823

Belyea, L. 1996. Separating the effects of litter quality and microenvironment on decomposition rates in a patterned peatland. Oikos 77, 529-539.

Boddy, L. 1993. Saprotrophic cord-forming fungi: warfare strategies and other ecological aspects. Mycological Research 97(6), 641-655.

Brand, A., Gow, N. 2009. Mechanisms of hypha orientation of fungi. Current Opinion in Microbiology 12, 350-357. http://dx.doi.org/10.1016/j.mib.2009.05.007

Cairney, J. 2005. Basidiomycete mycelia in forest soils: dimensions, dynamics and roles in nutrient distribution. Mycological Research 109(1), 7-20. http://dx.doi.org/10.1017/S0953756204001753

Curzon, M., D’Amato, A., Palik, B. 2014. Harvest residue removal and soil compaction impact forest productivity and recovery: Potential implications for bioenergy harvests. Forest Ecology and Management 329, 99-107. http://dx.doi.org/10.1016/j.foreco.2014.05.056

Dowson, C., Rayner, A., Boddy, L. 1986. Outgrowth patterns of mycelial cord-forming basidiomycetes from and between woody resource units in soil. Journal of General Microbiology 132, 203-211.

Frey, S. \& Six, J., Elliott, E. 2003. Reciprocal transfer of carbon and nitrogen by decomposer fungi at the soillitter interface. Soil Biology \& Biochemistry 35, 1001-1004. http://dx.doi.org/10.1016/S0038-

0717(03)00155-X

Grover, S., Baldock, J. 2010. Carbon decomposition processes in a peat from the Australian Alps. European Journal of Soil Science 61, 217-230. http://dx.doi.org/10.1111/j.1365-2389.2009.01220.x 
Helmisaari, H-S., Kaarakka, L., Olsson, B. 2014. Increased utilization of different tree parts for energy purposes in the Nordic countries. Scandinavian Journal of Forest Research 29(4), 312-322.

http://dx.doi.org/10.1080/02827581.2014.926097

Hodge, A. 2004. The plastic plant: root responses to heterogeneous supplies of nutrients. New Phytologist 162, 9-24. http://dx.doi.org/10.1111/j.1469-8137.2004.01015.x

Holub, S., Terry, T., Harrington, C., Harrison, R., Meade, R. 2013. Tree growth ten years after residual biomass removal, soil compaction, tillage, and competing vegetation control in a highly-productive Douglas-fir plantation. Forest Ecology and Management 305, 60-66.

http://dx.doi.org/10.1016/j.foreco.2013.05.031

Karhu, K., Hilasvuori, E., Fritze, H., Biasi, C., Nykänen, H., Liski, J., Vanhala, P., Heinonsalo, J., Pumpanen J. 2016. Priming effect increases with depth in a boreal forest soil. Soil Biology and Biochemistry 99, 104-107. http://dx.doi.org/10.1016/j.soilbio.2016.05.001

Karlsson, H., Börjesson, P., Hansson, P-A., Ahlgren, S. 2014. Ethanol production in biorefineries using lignocellulosic feedstock - GHG performance, energy balance and implications of life cycle calculation methodology. Journal of Cleaner Production 83, 420-427. http://dx.doi.org/10.1016/j.jclepro.2014.07.029

Kuzyakov, Y., Friedel, J., Stahr, K. 2000. Review of mechanisms and quantification of priming effects. Soil Biology \& Biochemistry 32: 1485-1498.

Laine, J. 1989. Metsäojitettujen soiden luokittelu. (Summary: classification of peatlands drained for forestry). Suo $40,37-51$.

Leake, J., Donnelly, D., Saunders, E., Boddy, L., Read, D. 2001. Rates and quantities of carbon flux to ectomycorrhizal mycelium following ${ }^{14} \mathrm{C}$ pulse labeling of Pinus sy/vestris seedlings: effects of litter patches and interaction with a wood-decomposer fungus. Tree Physiology 21, 71-82.

Lindahl, B., Olsson, S. 2004. Fungal translocation - creating and responding to environmental heterogeneity. Mycologist 18(2), 79-88. http://dx.doi.org/10.1017/S0269915X04002046

Lindholm, E-L., Stendahl, J., Berg, S., Hansson, P-A. 2011. Greenhouse gas balance of harvesting stumps and logging residues for energy in Sweden. Scandinavian Journal of Forest Research 26, 586-594.

http://dx.doi.org/10.1080/02827581.2011.615337

Lloyd, J., Taylor, J.A. 1994. On the temperature dependence of soil respiration. Functional Ecology 8, 315323.

Mäkipää, R., Linkosalo, T., Komarov, A., Mäkelä, A. 2014. Mitigation of climate change with biomass harvesting in Norway spruce stands: are harvesting practices carbon neutral? Canadian Journal of Forest Research 45, 217-225. http://dx.doi.org/10.1139/cjfr-2014-0120

Mäkiranta, P., Laiho, R., Fritze, H., Hytönen, J., Laine, J., Minkkinen, K. 2009. Indirect regulation of heterotrophic peat soil respiration by water level via microbial community structure and temperature sensitivity. Soil Biology \& Biochemistry 41, 695-703. http://dx.doi.org/10.1016/j.soilbio.2009.01.004 
Mäkiranta, P., Laiho, R., Penttilä, T., Minkkinen, K. 2012. The impact of logging residue on soil GHG fluxes in a drained peatland forest. Soil Biology \& Biochemistry 48, 1-9.

http://dx.doi.org/10.1016/j.soilbio.2012.01.005

Mathijssen, P., Väliranta, M., Korrensalo, A., Alekseychik, P., Vesala, T., Rinne, J., Tuittila, E-S. 2016.

Reconstruction of Holocene carbon dynamics in a large boreal peatland complex, southern Finland.

Quaternary Science Reviews 142, 1-15. http://dx.doi.org/10.1016/j.quascirev.2016.04.013

Minkkinen, K., Laine, J. 1998. Long-term effect of forest drainage on the peat carbon stores of pine mires in Finland. Canadian Journal of Forest Research 28, 1267-1275.

Olajuyigbe, S., Tobin, B., Nieuwenhuis, M. 2014. The role of brash in augmenting forest site carbon capital and maintaining site nutrition in a Sitka spruce forest in Ireland. European Journal of Forest Research 133, 563-572. http://dx.doi.org/10.1007/s10342-014-0785-7

Pinheiro, J., Bates, D., DebRoy S., Sarkar D. and the R Development Core Team (2013). NIme: Linear and Nonlinear Mixed Effects Models. R package version 3.1-111. https://cran.r-project.org/package=nlme

Pritchard, S., Strand, A., McCormack, M., Davis, M., Oren, R. 2008. Mycorrhizal and rhizomorph dynamics in a loblolly pine forest during 5 years of free-air- $\mathrm{CO}_{2}$-enrichment. Global Change Biology 14, 1-13. http://dx.doi.org/10.1111/j.1365-2486.2008.01567.x

R Core Team (2013). R: A language and environment for statistical computing. R Foundation for Statistical Computing, Vienna, Austria. http://www.R-project.org/.

Repo, A., Känkänen, R., Tuovinen, J-P., Antikainen, R., Tuomi, M., Vanhala, P., Liski, J. 2012. Forest bioenergy climate impact can be improved by allocating forest residue removal. GCB Bioenergy 4, 202-212. http://dx.doi.org/10.1111/j.1757-1707.2011.01124.x

Roberts, S., Harrington, C., Terry, T. 2005. Harvest residue and competing vegetation affect soil moisture, soil temperature, $\mathrm{N}$ availability, and Douglas-fir seedling growth. Forest Ecology and Management 205, 333-350. http://dx.doi.org/10.1016/j.foreco.2004.10.036

Robinson, D. 1994. The responses of plants to non-uniform supplies of nutrients. New Phytologist 127, 635-674.

Simola, H., Pitkänen, A., Turunen, J. 2012. Carbon loss in drained forestry peatlands in Finland, estimated by re-sampling peatlands surveyed in the 1980s. European Journal of Soil Science 63, 798-807. http://dx.doi.org/10.1111/j.1365-2389.2012.01499.x

Staddon, P., Ramsey, C., Ostle, N., Ineson, P., Fitter, A. 2003. Rapid turnover of hyphae of mycorrhizal fungi determined by AMS microanalysis of ${ }^{14} \mathrm{C}$. Science 300, 1138-1140.

http://dx.doi.org/10.1126/science.1084269

Straková, P., Penttilä, T., Laine, J., Laiho, R. 2012. Disentangling direct and indirect effects of water table drawdown on above- and belowground plant litter decomposition: consequences for accumulation of organic matter in boreal peatlands. Global Change Biology 18, 322-335. http://dx.doi.org/10.1111/j.1365-

2486.2011.02503.x 
Taylor, B. 1998. Air-drying depresses rates of leaf litter decomposition. Soil Biology and Biochemistry 30(3), 403-412.

Thompson, W., Rayner, A. 1983. Extent, development and function of mycelial cord systems in soil. Transactions of the British Mycological Society 81(2), 333-345.

Tuomi, M., Thum, T., Järvinen, H., Fronzek, S., Berg, B., Harmon, M., Trofymow, J.A., Sevanto, S, Liski, J. 2009. Leaf litter decomposition - Estimates of global variability based on Yasso07 model. Ecological Modelling 220, 3362-3371. http://dx.doi.org/10.1016/j.ecolmodel.2009.05.016

Wall, A. 2008. Effect of removal of logging residue on nutrient leaching and nutrient pools in the soil after clearcutting in a Norway spruce stand. Forest Ecology and Management 256, 1372-1383. http://dx.doi.org/10.1016/j.foreco.2008.06.044

Wall, A., Hytönen, J. 2011. The long-term effects of logging residue removal on forest floor nutrient capital, foliar chemistry and growth of a Norway spruce stand. Biomass and Bioenergy 35, 3328-3334. http://dx.doi.org/10.1016/j.biombioe.2010.08.063

Vargas, R., Allen, M. 2008. Dynamics of fine root, fungal rhizomorphs, and soil respiration in a mixed temperate forest: integrating sensors and observations. Vadose Zone Journal 7, 1055-1064. http://dx.doi.org/10.2136/vzj2007.0138

Wei, X., Liu, W., Waterhouse, J., Armlede, M. 2000. Simulations on impacts of different management strategies on long-term site productivity in lodgepole pine forests of the central interior of British Columbia. Forest Ecology and Management 133, 217-229.

Wells, J., Hughes, C., Boddy, L. 1990. The fate of soil-derived phosphorus in mycelial cord systems of Phanerochaete velutina and Phallus impudicus. New Phytologist 114, 595-606.

Vitt, D., Wieder, R., Scott, K., Faller, S. 2009. Decomposition and Peat Accumulation in Rich Fens of Boreal Alberta, Canada. Ecosystems 12, 360-373. http://dx.doi.org/10.1007/s10021-009-9228-6 

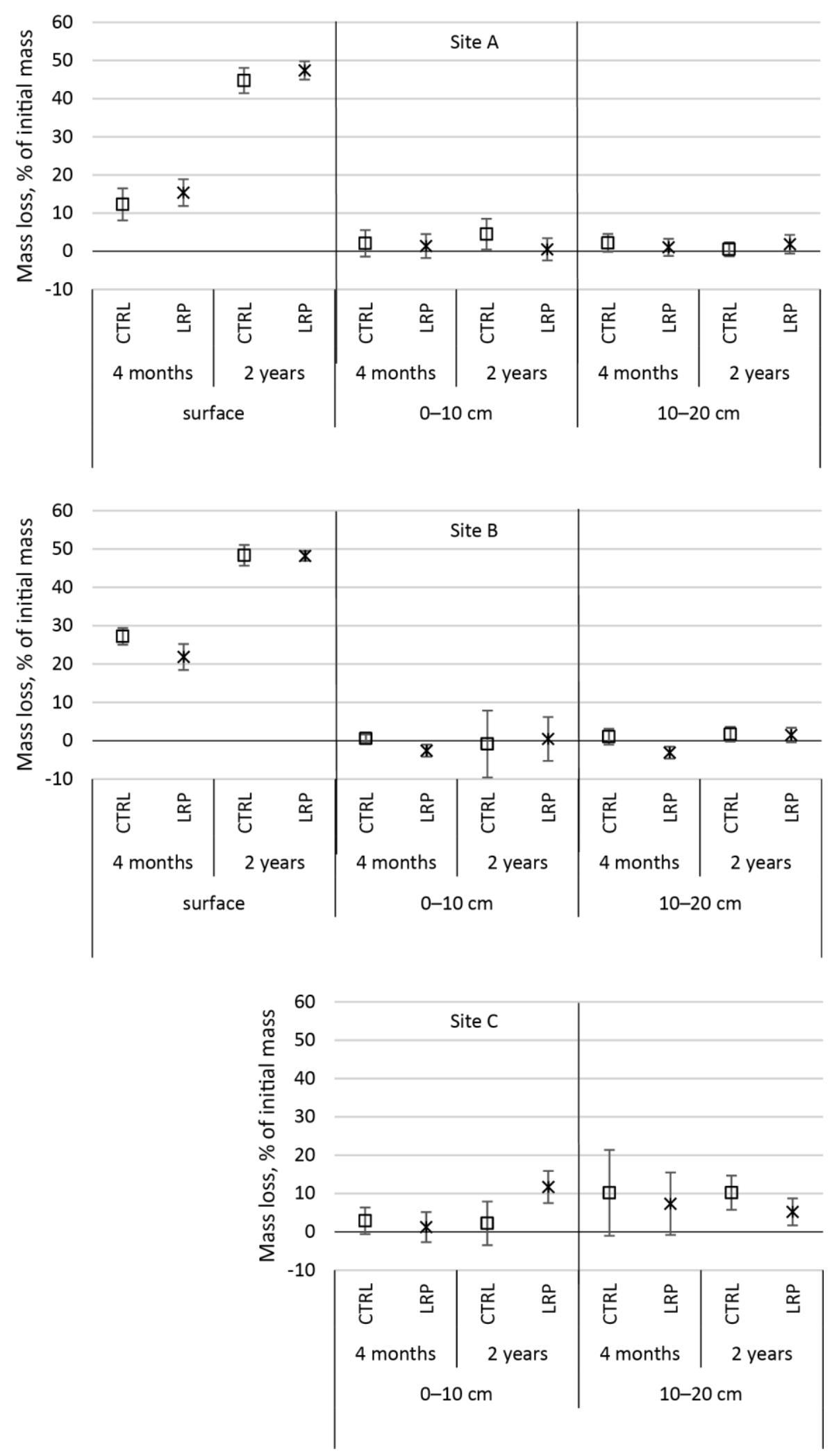

Figure 1. Mean mass loss (\% of initial mass) of the humus layer (surface) and peat incubated in soil at control (CTRL) and logging residue pile (LRP) plots June-September 2013 (4 months) and June 2013-May 2015 (2 years). Error bars are standard deviations. At site $C$, results for humus layer are missing because the data on initial surface layer moisture content were lost. 


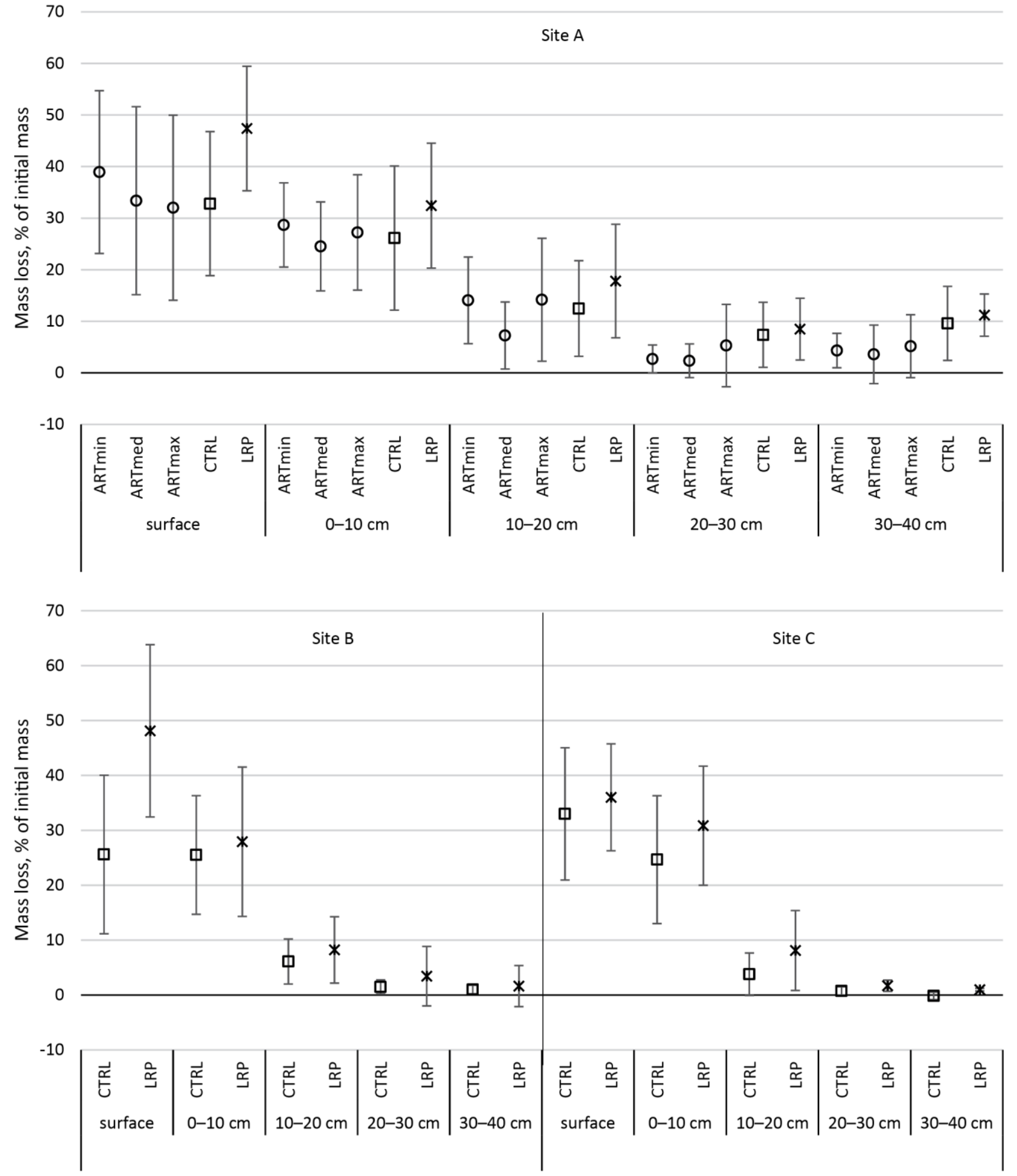

Figure 2. Mean mass loss (\% of initial mass) of the cellulose strips incubated in soil June-September 2013 with (LRP, crosses) and without (CTRL, squares) logging residue piles at sites $A, B$ and $C$, and with artificial piles (ART $\min / \mathrm{med} / \mathrm{max}$, circles) at site A. Error bars are standard deviations. 

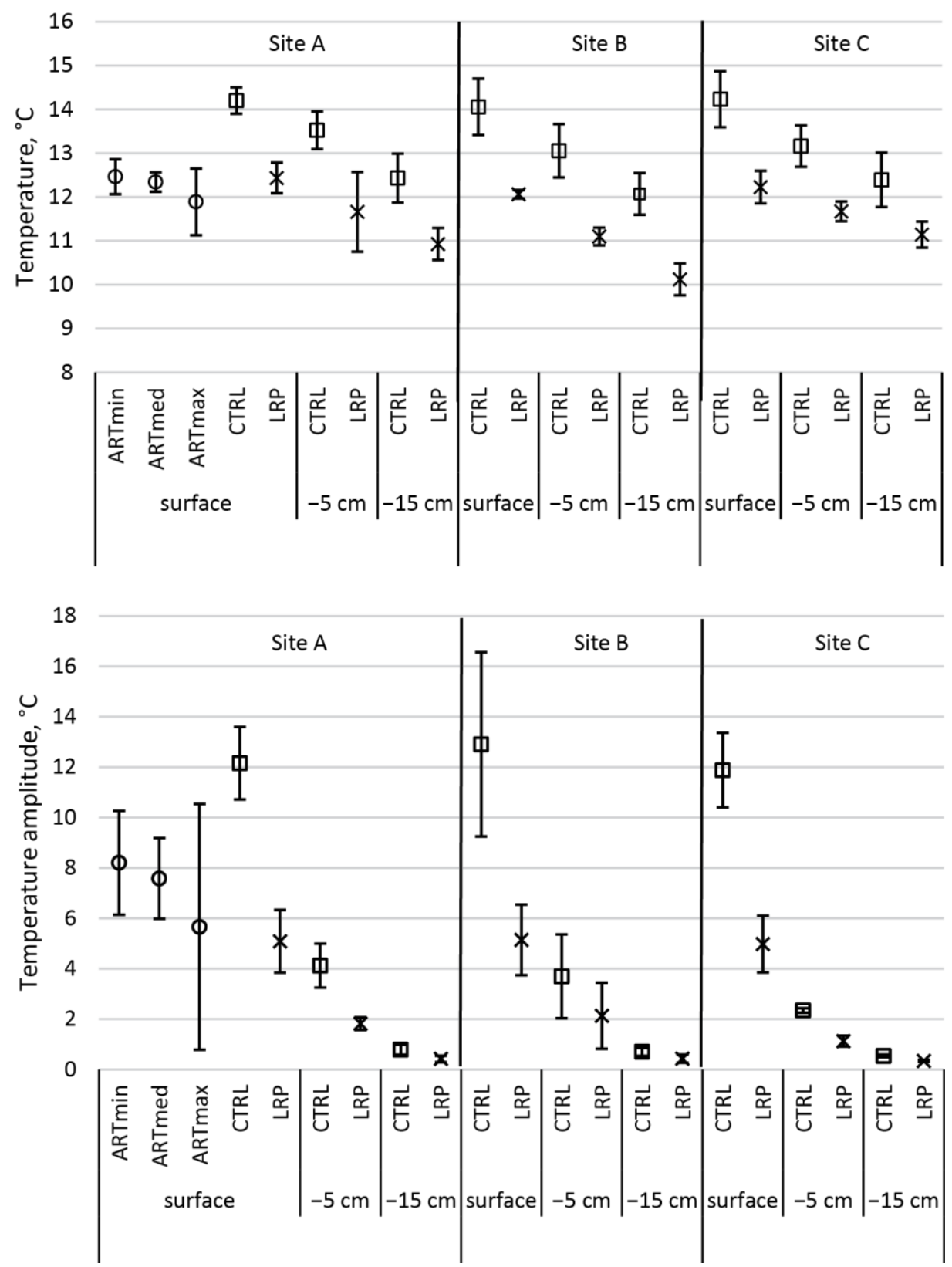

Figure 3. Mean temperature and mean daily temperature amplitude (daily max - daily $\mathrm{min}$ ) at control plots and treatment plots at the study sites during June-September 2013. Error bars are between plot standard deviations. 
Site A
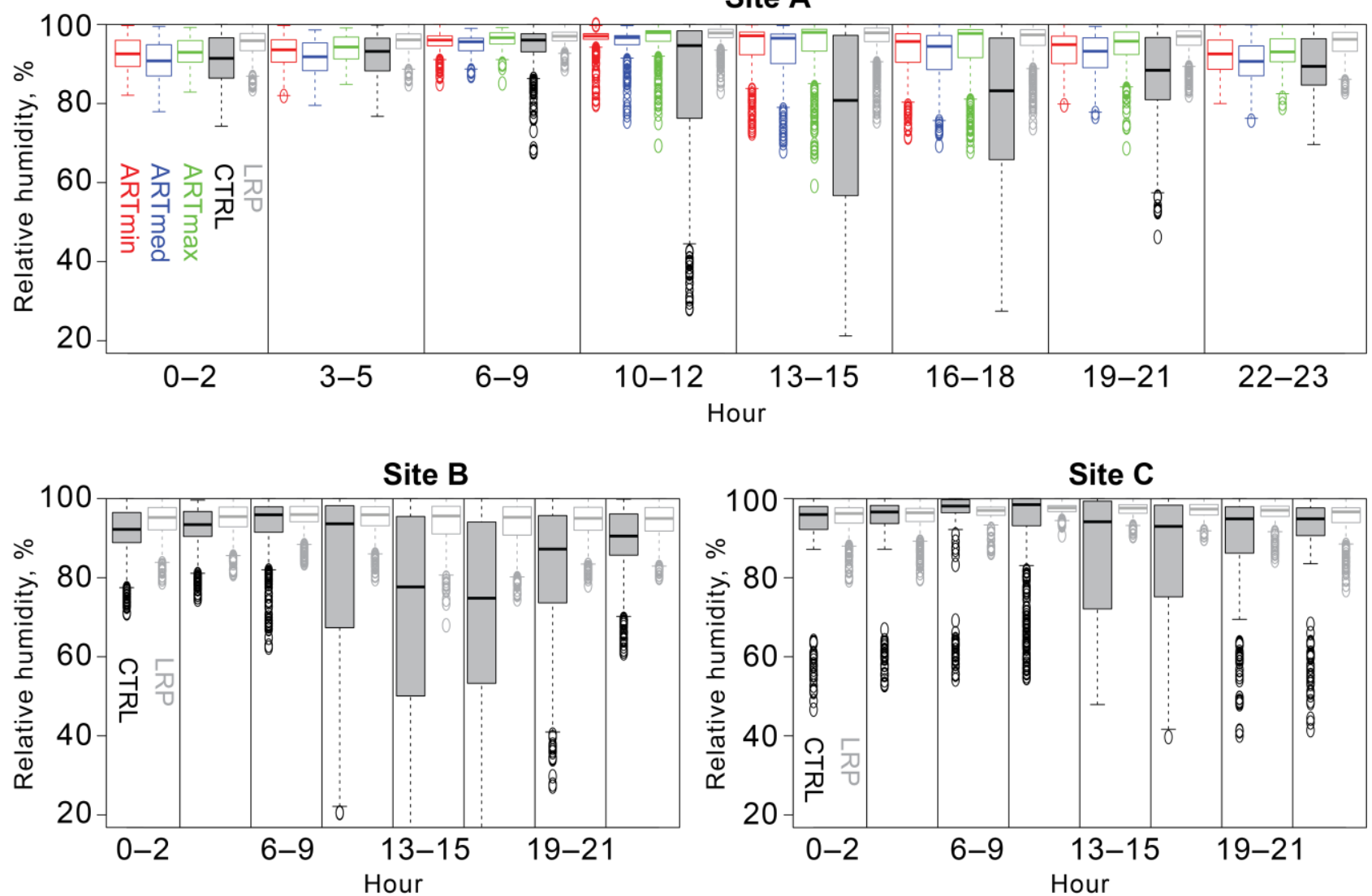

Figure 4. The diurnal cycle (hour interval on $x$ axis) of relative humidity (\%) at the moss layer-atmosphere interface at different sites and treatments during July $5^{\text {th }}$-September $30^{\text {th }}, 2013$. Box delimits the second and third quartiles and the line inside the box is the median. Whiskers delimit the data range within 1.5 times the interquartile range. Circles are data outside the whiskers. 
Site A

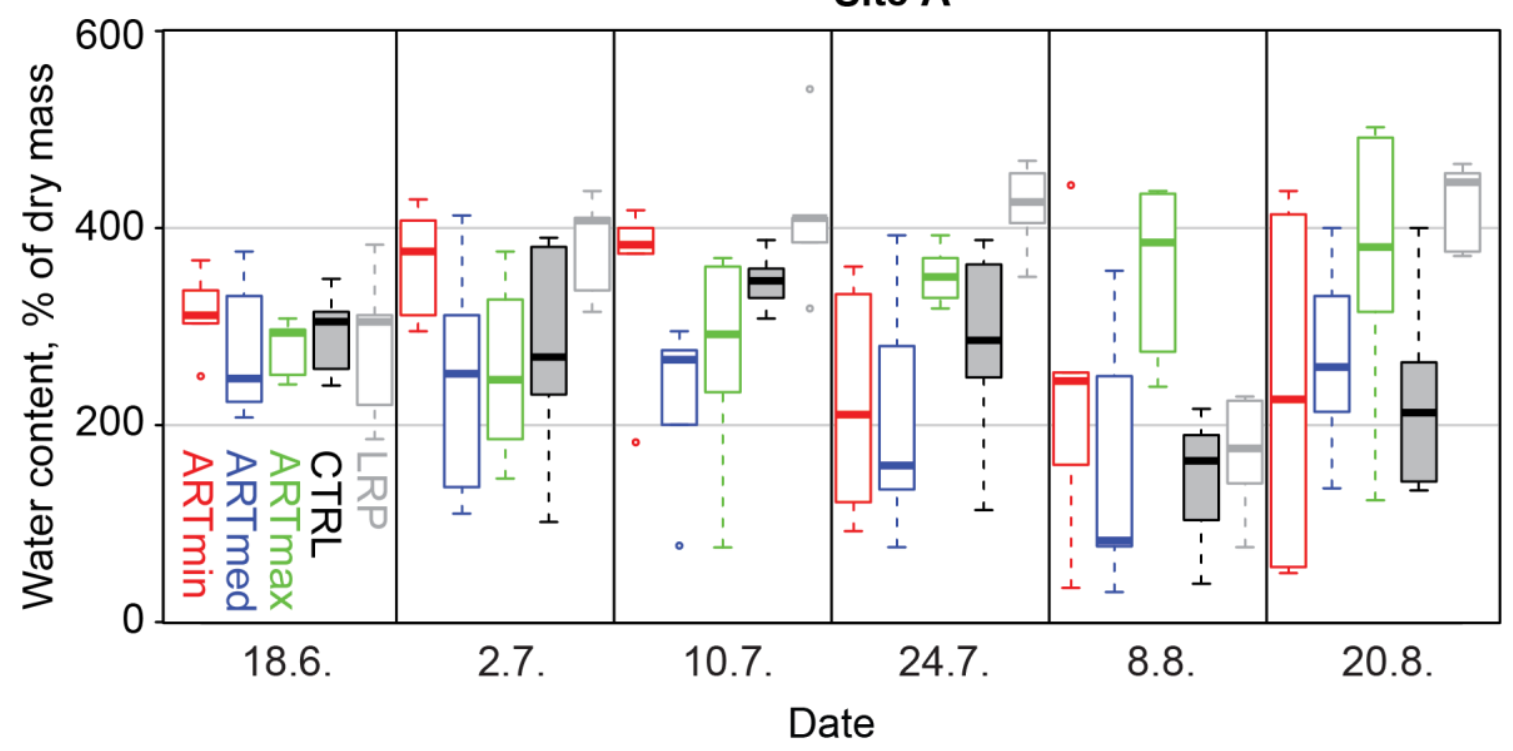

Site B

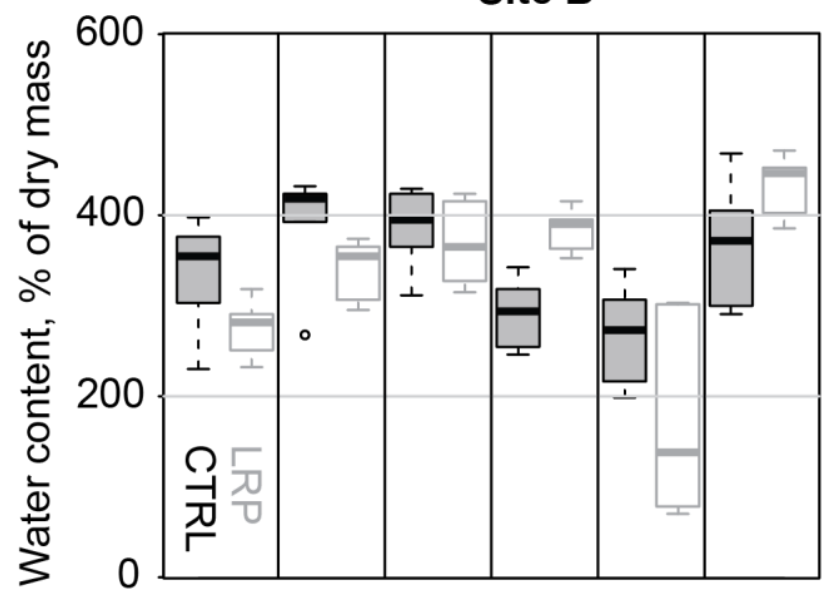

Site C

18.6. 2.7. 10.7. 24.7. 8.8. 20.8. 18.6. 2.7. 10.7. 24.7. 8.8. 20.8.

Date

Date

Figure 5. Gravimetric water content of tea bags incubated at different sites and treatments. See figure 4 for the explanation of the boxplot. 


\section{Previous theoretical framework}

Chamber measurement at CTRL plot:

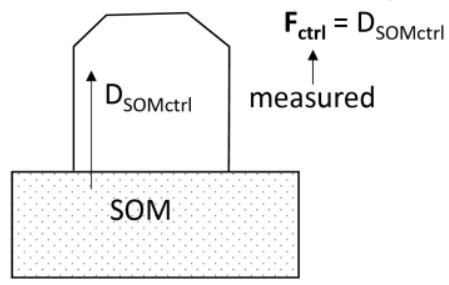

Chamber measurement at LRP plot:

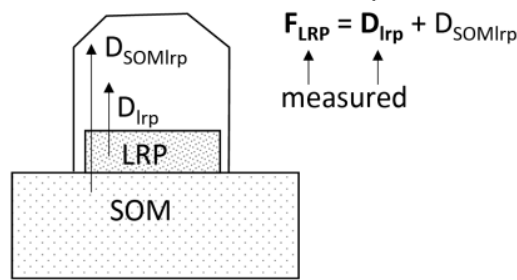

Result of Mäkiranta et al. 2012:

$F_{\text {LRP }}-D_{\text {Irp }}=D_{\text {SOMlrp }}>D_{\text {SOMctrl }}=F_{\text {ctrl }}$

$=>$ LRP increases $D_{\text {SOM }}$
This study

Decomposition measurement at CTRL plot:

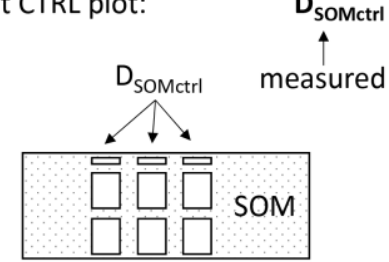

Decomposition measurement at LRP plot:

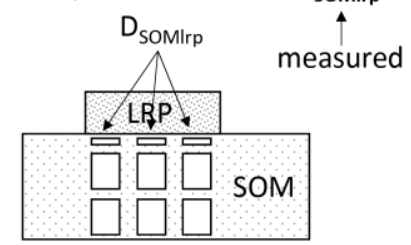

Result of this study:

$\mathrm{D}_{\text {SOMIrp }} \approx \mathrm{D}_{\text {SOMctrl }}$
Improved theoretical framework:

Chamber measurement at CTRL plot:

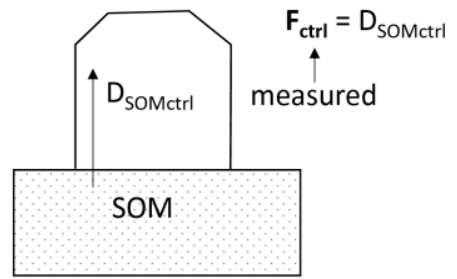

Chamber measurement at LRP plot:

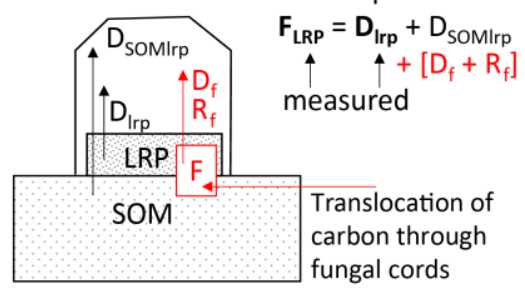

Result of Mäkiranta et al. 2012:

$F_{\text {LRP }}-D_{\text {Irp }}=D_{\text {SOMlrp }}+\left[D_{f}+R_{f}\right]>D_{\text {SOMctrl }}=F_{\text {ctrl }}$ $\Rightarrow$ LRP does not increase $D_{\text {som }} \underset{\text { Agreement }}{\longrightarrow} \Rightarrow$ LRP increases $D_{\text {som }}$ or causes $\left[D_{f}+R_{f}\right]$

Figure 6. Inclusion of fungal biomass carbon storage $(F)$ and $\mathrm{CO}_{2}$ fluxes caused by its respiration $\left(\mathrm{R}_{\mathrm{f}}\right)$ and decomposition $\left(D_{f}\right)$ into the theoretical framework (I => III) used to interpret the results of Mäkiranta et al. (2012) eliminates the apparent disagreement (I vs. II) with the results of this study. LRP = carbon storage of logging residues, $\mathrm{SOM}=$ carbon storage of soil organic matter, $\mathrm{D}=$ decomposition, $\mathrm{F}=$ chamber measured $\mathrm{CO}_{2}$ flux. 
Table 1. Basic information of the study sites. Site types are according to the classification of Laine (1989, See Vasander \& Laine, 2008). Coordinates are given according to the ETRS89 projection ( $\approx$ WGS84). WT = mean water table depth from soil surface for June-August, 2013. $\mathrm{C} / \mathrm{N}=$ carbon to nitrogen ratio of the top $10 \mathrm{~cm}$ of soil. $\mathrm{BD}=$ bulk density of the top $20 \mathrm{~cm}$ of soil. $\mathrm{se}=$ standard error of mean.

\begin{tabular}{|l|l|l|r|r|r|r|}
\hline Site & Site type & Coordinates & $\begin{array}{r}\text { Elevation } \\
(\mathrm{m} \text { a.s.I. })\end{array}$ & WT \pm se $(\mathrm{cm})$ & C/N \pm se & $\begin{array}{r}\text { BD } \pm \text { se } \\
\left(\mathrm{kg} \mathrm{m}^{-3}\right)\end{array}$ \\
\hline A & Dwarf shrub & $61^{\circ} 50.164^{\prime} \mathrm{N}, 24^{\circ} 12.597^{\prime} \mathrm{E}$ & 163 & $65 \pm 5$ & $34.3 \pm 0.9$ & $108 \pm 5$ \\
\hline B & $\begin{array}{l}\text { Vaccinium } \\
\text { myrtillus }\end{array}$ & $61^{\circ} 49.644^{\prime} \mathrm{N}, 24^{\circ} 12.874^{\prime} \mathrm{E}$ & 163 & $31 \pm 5$ & $28.6 \pm 0.3$ & $135 \pm 8$ \\
\hline C & Dwarf shrub & $61^{\circ} 49.518^{\prime} \mathrm{N}, 24^{\circ} 12.336^{\prime} \mathrm{E}$ & 162 & $21 \pm 1$ & $40.0 \pm 0.5$ & $83 \pm 7$ \\
\hline
\end{tabular}


Table 2. Tree stand characteristics before clearfelling. $N=$ stem number, $G=$ basal area, $D_{1.3}=$ mean diameter at breast height, $\mathrm{H}=$ mean height, $\mathrm{V}=$ stem volume.

\begin{tabular}{|c|c|c|c|c|c|}
\hline Species & $\mathrm{N}$, trees/ha & G, $\mathrm{m}^{2} / \mathrm{ha}$ & $\mathrm{D}_{1.3}, \mathrm{~cm}$ & $\mathrm{H}, \mathrm{m}$ & $\mathrm{V}, \mathrm{m}^{3} / \mathrm{ha}$ \\
\hline \multicolumn{6}{|c|}{ Site A } \\
\hline Pine & 500 & 25.7 & 25.3 & 19.4 & 241.8 \\
\hline Spruce & 50 & 0.3 & 7.7 & 7.8 & 1.2 \\
\hline Birch & 375 & 2.1 & 7.5 & 7.5 & 11.3 \\
\hline All species & 925 & 28.0 & 17.2 & 13.9 & 254.3 \\
\hline \multicolumn{6}{|c|}{$\underline{\text { Site B }}$} \\
\hline Pine & 300 & 12.7 & 22.3 & 17.7 & 116.2 \\
\hline Spruce & 525 & 4.0 & 9.3 & 9.2 & 22.1 \\
\hline Birch & 250 & 1.8 & 8.5 & 8.3 & 10.8 \\
\hline All species & 1075 & 18.4 & 12.7 & 11.3 & 149.1 \\
\hline \multicolumn{6}{|c|}{$\underline{\text { Site C }}$} \\
\hline Pine & 600 & 20.9 & 20.3 & 16.7 & 182.1 \\
\hline Spruce & 75 & 0.3 & 6.6 & 6.7 & 1.1 \\
\hline Birch & 150 & 0.6 & 6.9 & 7.1 & 2.5 \\
\hline All species & 825 & 21.7 & 16.6 & 14.1 & 185.7 \\
\hline
\end{tabular}


Table 3. Projection coverage (\%) and mean and maximum thickness $(\mathrm{cm})$ of logging residue piles $( \pm$ standard error of mean) at each site.

\begin{tabular}{lrrr}
\hline Site & Coverage, $\%$ & Mean thickness, $\mathrm{cm}$ & Max thickness, $\mathrm{cm}$ \\
\hline $\mathrm{A}$ & $23 \pm 5$ & $22 \pm 3$ & 60 \\
$\mathrm{~B}$ & $35 \pm 6$ & $15 \pm 3$ & 45 \\
$\mathrm{C}$ & $23 \pm 5$ & $16 \pm 3$ & 70 \\
\hline
\end{tabular}


Table 4. Mean cellulose mass loss (\% of initial mass) at the control and LRP plots and the effect of LRP (both absolute units and relative units (effect of LRP / mass loss at CTRL). Letters $a$ and $b$ denote soil layers not having statistically significantly different $(p<0.05)$ mass loss $(C T R L)$ or effect of LRP on mass loss $(L R P)$. $p$ is the significance of the LRP effect of models fitted separately for each layer.

\begin{tabular}{lrrrrrrr}
\hline & & \multicolumn{2}{c}{ Mass loss } & & \multicolumn{3}{c}{ Effect of LRP } \\
\cline { 1 - 4 } \cline { 6 - 8 } Layer & & CTRL, \% & LRP, \% & & Abs., \%-units & p & Rel., \% \\
\hline surface & & $30.5^{\mathrm{a}}$ & 43.9 & & $13.5^{\mathrm{a}}$ & 0.0009 & 44.2 \\
$0-10 \mathrm{~cm}$ & & $25.4^{\mathrm{a}}$ & 30.5 & & $5.1^{\mathrm{b}}$ & 0.16 & 20.0 \\
$10-20 \mathrm{~cm}$ & & $7.5^{\mathrm{b}}$ & 11.4 & & $4.0^{\mathrm{b}}$ & 0.10 & 53.5 \\
$20-30 \mathrm{~cm}$ & & $3.2^{\mathrm{b}}$ & 4.7 & & $1.5^{\mathrm{b}}$ & 0.35 & 47.5 \\
$30-40 \mathrm{~cm}$ & & $3.5^{\mathrm{b}}$ & 4.7 & & $1.3^{\mathrm{b}}$ & 0.52 & 36.4 \\
\hline mean & $\mathbf{1 4 . 0}$ & $\mathbf{1 9 . 1}$ & & $\mathbf{5 . 1}$ & & $\mathbf{3 6 . 4}$ \\
\hline
\end{tabular}


Appendix 1. Average mass losses (\% of initial dry mass) and standard deviations for humus (surface) and peat samples. This data was used in Figure 1.

A

Average Standard deviation

$\begin{array}{cc}\text { surface } & \\ \text { 4 months } & \\ \text { CTRL } & 12.3 \\ \text { LRP } & 15.4 \\ \text { 2 years } & \\ \text { CTRL } & 44.7 \\ \text { LRP } & 47.4 \\ \text { 0-10 cm } & \end{array}$

4 months

CTRL

LRP

2 years

CTRL

LRP

10-20 cm

4 months

$\begin{array}{ll}\text { CTRL } & 2.2 \\ \text { LRP } & 1.0\end{array}$

2 years

CTRL

LRP

B

surface

4 months

CTRL

LRP

27.2

2 years

CTRL
2.1

1.4

4.5

0.5

2.2

1.0

0.5

1.8

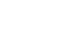

LRP

0-10 cm

4 months

CTRL

LRP

2 years

CTRL

LRP

3.3

2.4

3.5

3.1

4.0

2.9

2.4

2.2

1.8

2.5

3.5

3

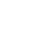

.5

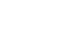

0

2.4

2

1.8

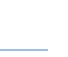


Histogram of subset(turve, stdt $==$ stdtu)\$mass.los Histogram of subset(turve, stdt $==$ stdtu)\$mass.los Histogram of subset(turve, stdt $==$ stdtu)\$mass.los Histogram of subset(turve, stdt $==$ stdtu)\$mass.los
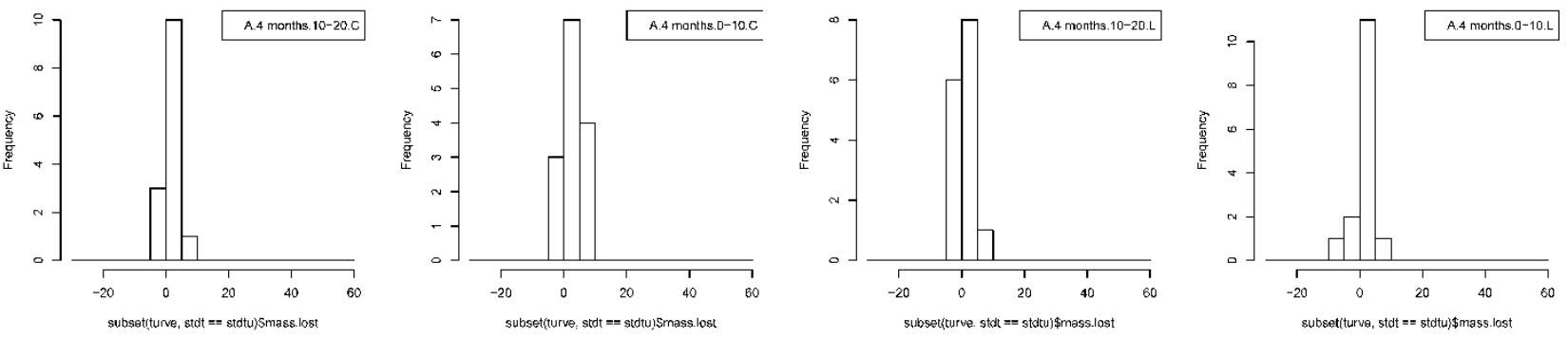

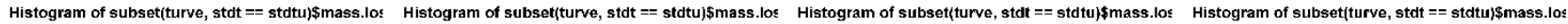
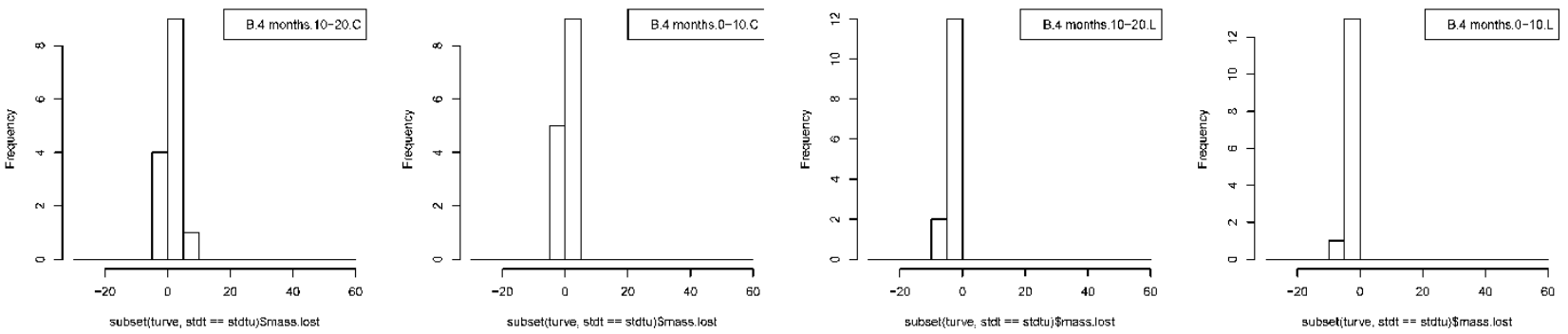

Histogram of subset(turve, stdt $==$ stdtu)\$mass.los Histogram of subset(turve, stdt $==$ stdtu)\$mass. los Histogram of subset(turve, stdt $==$ stdtu)\$mass.los Histogram of subset(turve, stdt $==$ stdtu)\$\$nass.los
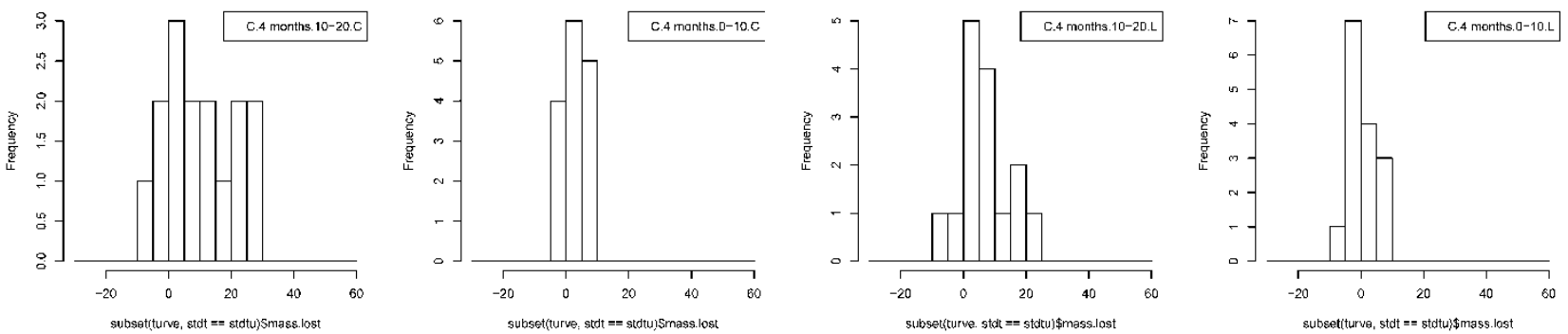

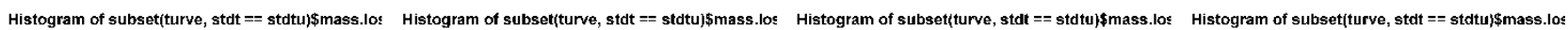
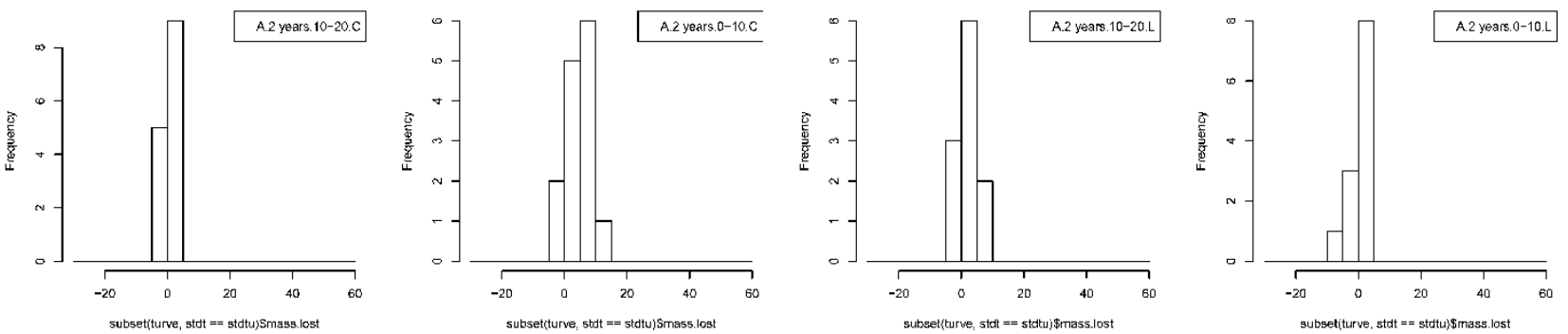
Histogram of subset(turve, stdt == stdtu)\$mass.los Histogram of subset(turve, stdt == stdtu)\$mass. los Histogram of subset(turve, stdt == stdtu)\$mass.los Histogram of subset(turve, stdt == stdtu)\$mass.los
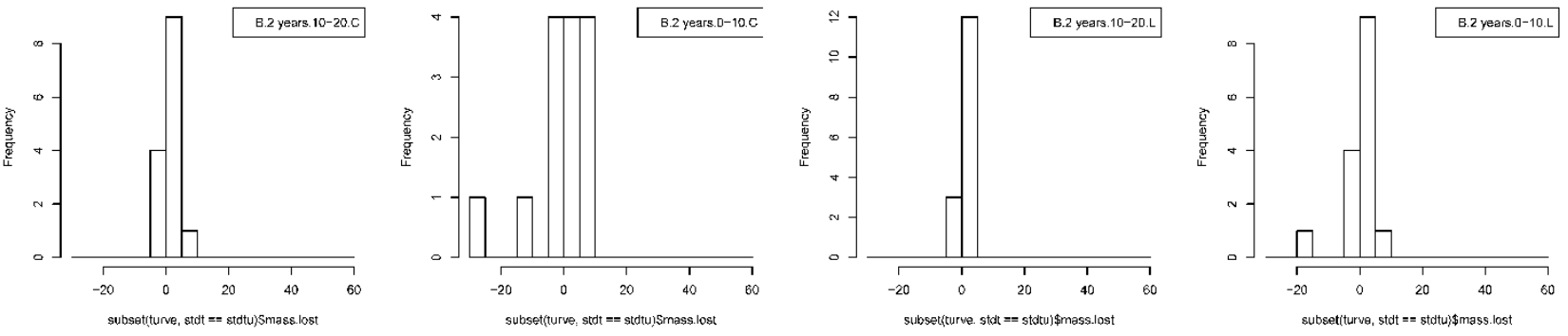

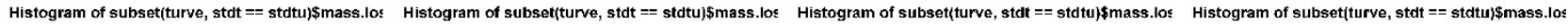
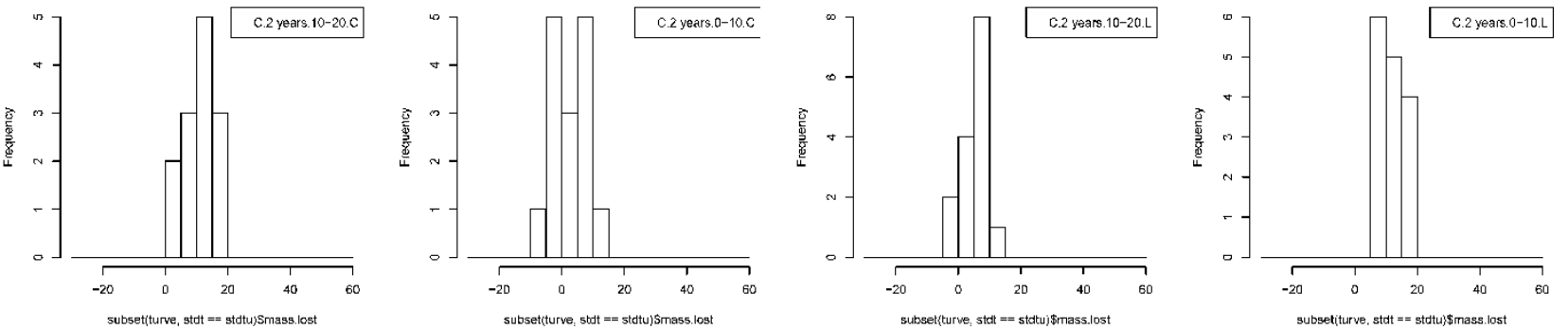

Histogram of subset(turve, stdt =s stdtu)\$mass.los Histogram of subset(turve, stdt == stdtu)\$mass. los Histogram of subset(turve, stdt == stdtu)\$mass.los Histogram of subset(turve, stdt $==$ stdtu)\$\$nass.los
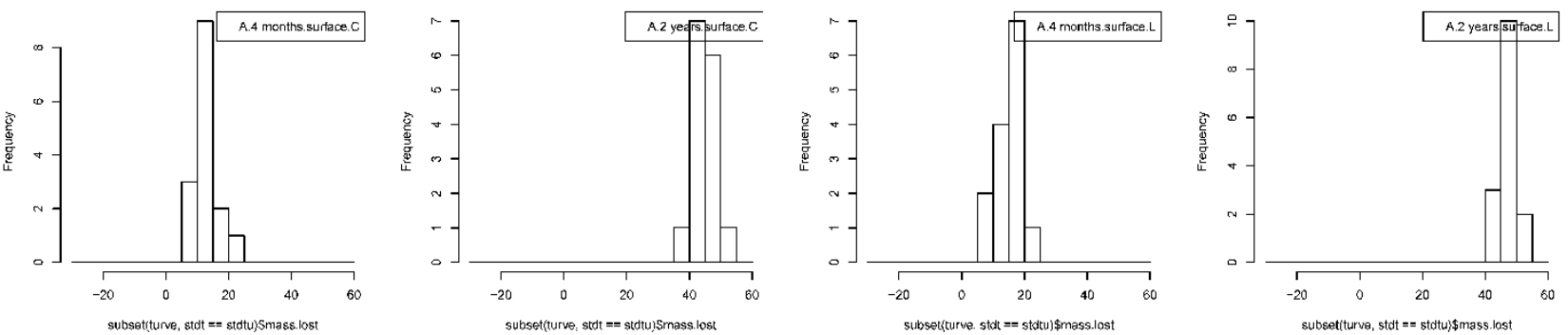

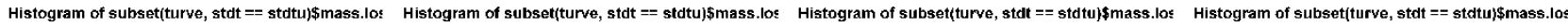
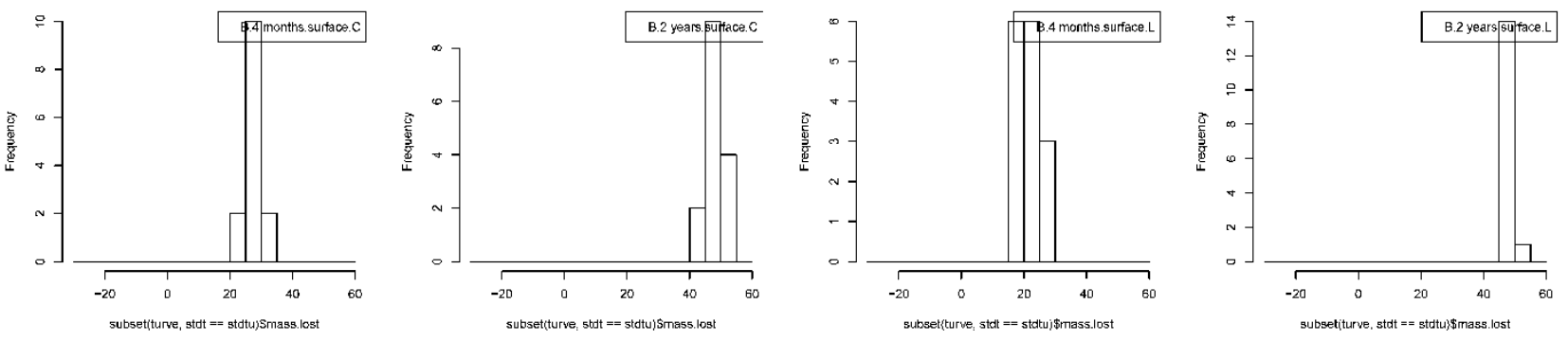
Appendix 3. Monthly means of temperature and daily temperature amplitude (daily max - daily min) at different soil depths for each logging residue (LPR), control (CTRL) and artificial logging residue (ART) plot at the study site A during June-September 2013. Notice the varying scales for temperature amplitude.
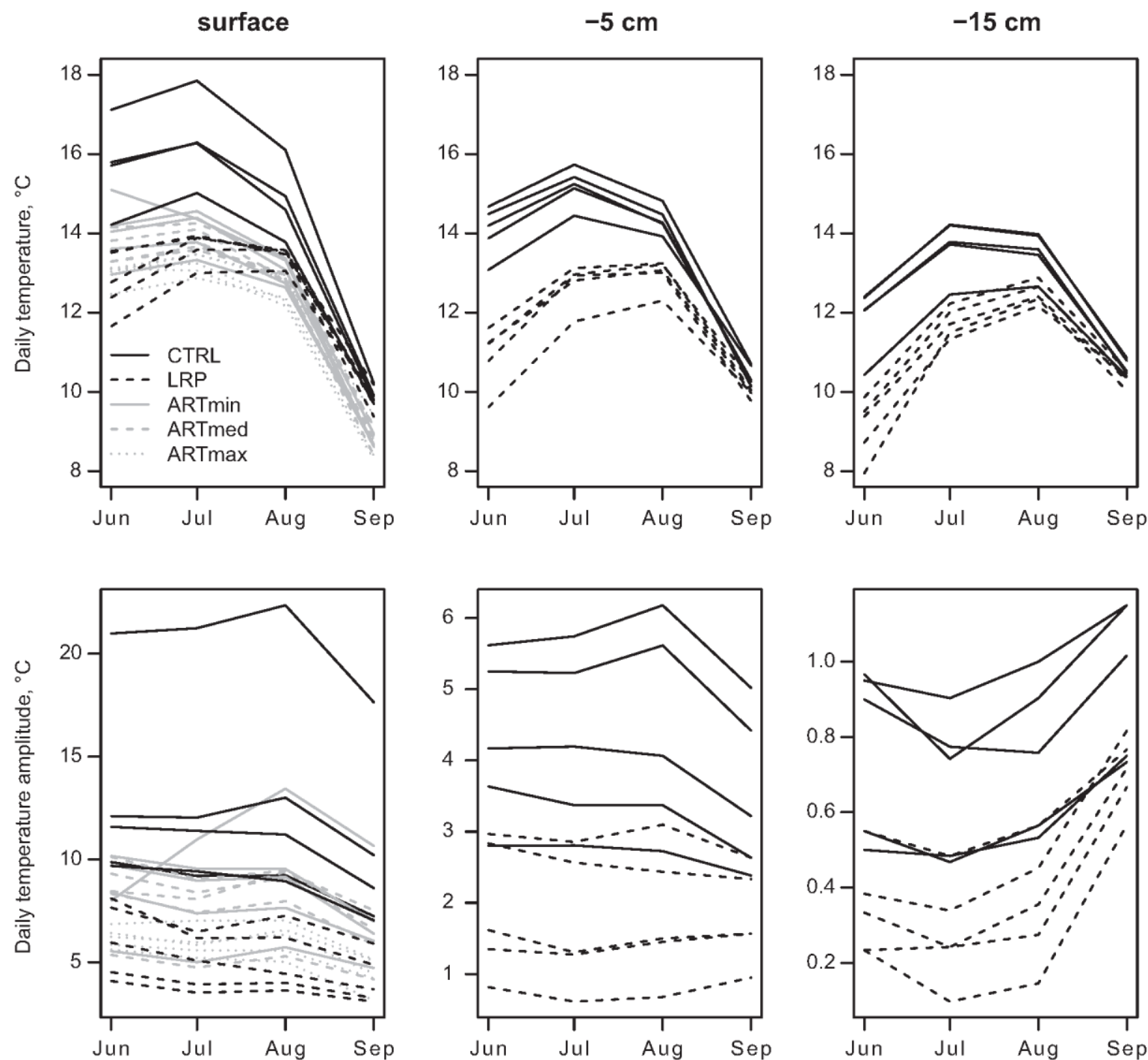
Appendix 4. Daily mean air temperature and daily precipitation at the Siikaneva measurement station (see Mathijssen et al. 2016 for site description), located one kilometer away from the study sites.

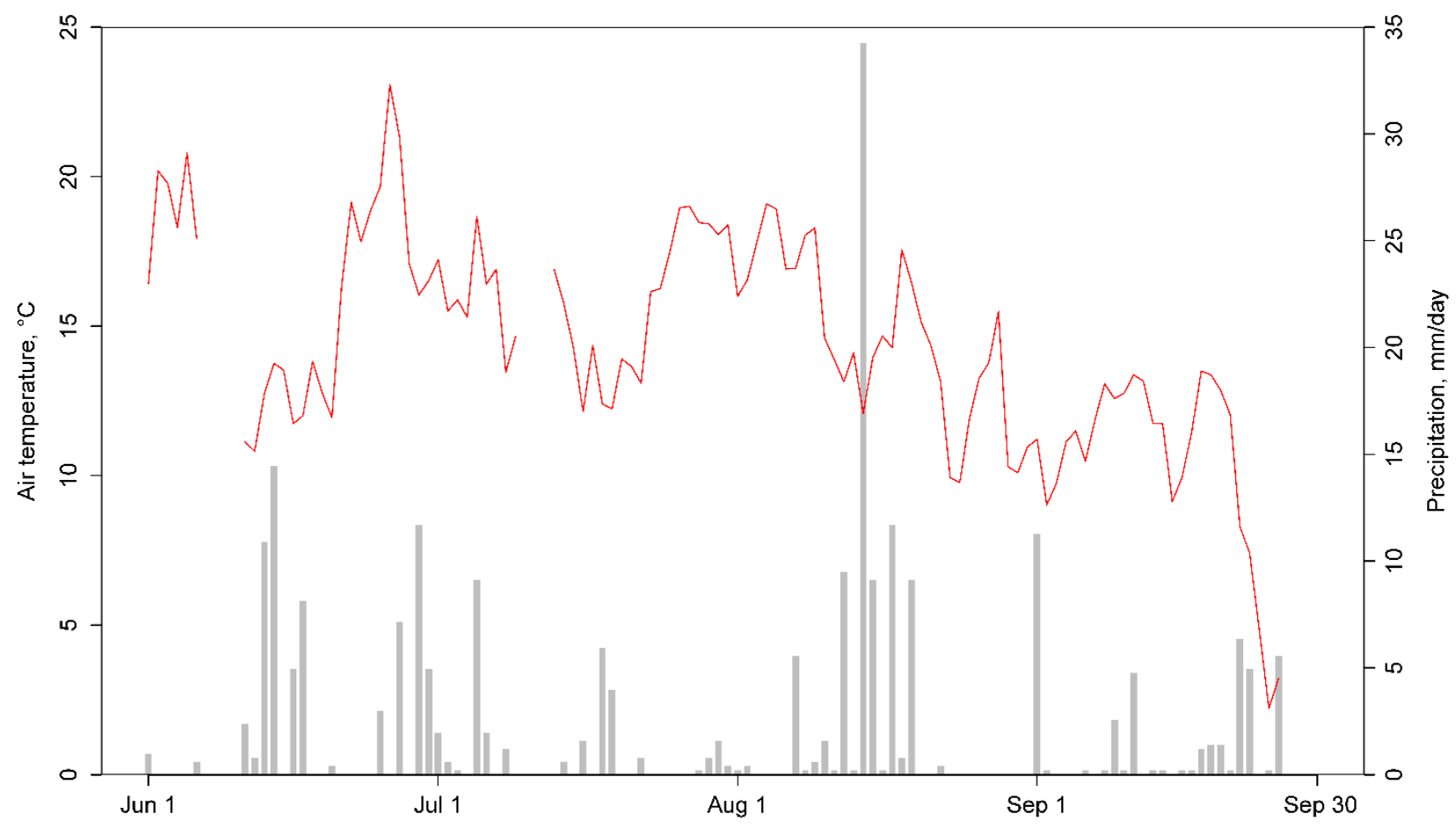

